\title{
Interethnic Tolerance of Population of Small Towns of Russia
}

\author{
Olga Fomina and Tamara Volchenkova \\ Murom Institute of Vladimir State University, 602264, Orlovskaya str., 23, Murom, Vladimir region, Russia
}

\begin{abstract}
The article gives the results of the sociological research on the problems of tolerance and migration in the central region of Russia. The mechanism of sociological interviewing of the population of small towns of Vladimir region with the help of students-volunteers is described. The existence of the problem in the field of cross-cultural relations between the representatives of the native population of Vladimir region and the representatives of national diasporas of small towns is confirmed. The practical significance of the research done is represented by the data, which served as a basis for recommendations to the bodies of self-government, social, educational institutions and mass media of Vladimir region on the formation of modern norms of ethics, law and tolerance in the community.
\end{abstract}

\section{Page layout}

Harmonious development of the modern Russian society is connected with the problem of diversity of cultures, existing in the same area, because it presupposes the ability of getting along with the people different in national, religious and cultural aspects living on the same territory. In the post-soviet period our country went through a hard socio-economic crisis, which had made its mark on all spheres of the life activity of the society, which entailed the change of the attitude of the native population of Russia towards the representatives of other nationalities. [1]

Everyday dozen thousands of people come to Russia as migrants, looking for work and worthy living conditions, refugees, saving their families from aftereffects of armed conflicts and hunger, and "pseudorefugees", hiding from law enforcement bodies or from military service in the army of their states, just wishing to live on social allowance, to get a favorable status of a refugee and a residence permit.

However the native population, especially living in the regions with a low level of economic development, does not share the views of the government on the problems of migrants.

Nowadays the world community faces socio-negative consequences of the uncontrolled reception of refugees and migrants. Mass disorders, taking place in the streets of France, Germany and Great Britain, a criminogenic situation in the blocks of migrants, unwillingness to work and life on social allowance and income from criminal activities, gave rise to a number of protest demonstrations and meetings the native population in Europe. [2]

In connection with this, the problem of cultural interaction and tolerant attitude to the representatives of different nationalities and cultures on the territory of Russia becomes important.[12]

In 2017 a group of researchers of Murom Institute of Vladimir State University under the supervision of Olga Fomina and Tamara Volchenkova conducted a sociological research studying the attitude of small town citizens of Vladimir region to representatives of other nationalities and migrants.

The sociological research done included several stages:

1. Studying theoretical materials on the problem to be researched [1 -13].

2. Preparation of the research. This stage consisted of thinking over the objective, working out a program and plan, determining the means and dates of conducting the research and selecting methods of analyzing and processing sociological information.

3. Collection of primary sociological information (non-generalized data in different forms - notes of researchers, answers of the interviewed, commentaries of interviewers).

4. Preparation of collected information for processing and processing the information received itself.

5. Analysis of the processed information, preparation of a scientific report on the results of the research, as well as formulation of conclusions, working out recommendations and proposals for mass media and educational institutions of Vladimir region.

Social phenomenon, the conducted sociological research was descriptive. The study was carried out in accordance with a full worked out program on the basis of tested tools.

A descriptive research is usually applied in the cases when a rather great community of people differing in various characteristics serves as an object of the research. It can be a population of a town, district, region

* Corresponding author: olgazemskova@inbox.ru 
where people of different age categories, a level of education, marital status, material security, etc., live and work.[10]

Selective public inquiry was used as a tool of the research. It is a sociological method of receiving information, in the course of which respondents (people being interviewed) are given specially selected questions and asked to answer them in a written or oral form.

A public inquiry is the most widespread type of a sociological study and the most widely used method of collecting primary information. By means of it, $70-$ $90 \%$ of all sociological data are collected.[6]

Questionnaire was chosen by us as a form of public

inquiring. A respondent fills in the questionnaire in the presence of an interviewer or without him.

In the course of the investigation, the problem under study was the attitude of citizens to such social phenomena as tolerance, xenophobia, cultural identity and assimilation.[5] For conducting the research, we have developed two questionnaires "The attitude of citizens to tolerance, migration and national minorities" and "Tolerance and xenophobia".

The main task of the questionnaire "Attitude of citizens to tolerance, migration and national minorities" was a possibility to discover on the basis of answers:

1. Understanding or personal interpretation by Vladimir region citizens of the basic terms, notably: tolerance, extremism, migration, national minorities.

2. Attitude of citizens to representatives of other nationalities, both living on their historical territory and to newly arrived ones.

3. Opinions of citizens concerning the reason of interethnic conflicts and terrorist acts.

4. Do citizens support the activity of youth organizations of extremist trend, if they do, then why?

The tasks of the second questionnaire "Tolerance and xenophobia" were:

1. Revealing understanding by Vladimir region citizens, the formulation of such concepts as xenophobia, tolerance and nationalism.

2. Assessment of the attitude of citizens to such categories of the population as migrants and refugees.

3. Assessment of the interethnic tension level in the town or settlement, where a respondent lives.

4. Revealing demonstrations of interethnic intolerance of the interviewed to representatives of other nationalities.

It should be noted that the public inquiry put an objective to study a gradation of views on the same problems of Vladimir region citizens of different age categories.

Sociological interviewing took place in the towns of Vladimir region with the population from 20 to 100 thousand citizens: Murom, Gorokhovetz, Melenky and Vyazniky. The total number of the interviewed reached 1000 people, 4,2\% of questionnaires were sorted out as containing wittingly unreliable data (incompatible answers), as well as spoilt with ruffian-like aims.

The method of direct interviewing and survey by questionnaire of citizens was used. Public inquiry was conducted by students-volunteers of Murom Institute of Vladimir State University, they also took part in statistic data processing of the survey by questionnaire. Statistic data was taken according to the age categories (youth aged 17-20, citizens aged 26-40, citizens aged 41-55, seniors aged 56-70, and according to the social status of respondents (education level, social status).

On the basis of the survey by questionnaire one can draw a conclusion, that a greater part of the citizens of Vladimir region have the right conception of such notions as tolerance( $87 \%$ of the interviewed), extremism ( $84 \%$ of respondents) and terrorism $(57 \%$ of the participants of the survey). The results, received in the course of research, showed that opinions of the citizens of Vladimir region on the topic of inquiry are quite opposite.

So, answering the question: "Do you agree that every nation should live on its historic territory?" $46 \%$ of respondents expressed the opinion that "Anybody can live anywhere", $54 \%$ of the interviewed, on the contrary, think that "Every nation should live only on its historic territory".

$21 \%$ of the interviewed react positively to marriages between representatives of different nationalities, 53\% have not yet defined their attitude to such unions, among young people $38 \%$ of respondents react negatively to such unions, and $51 \%$ of the respondents from this age category found it difficult for them to answer this question.

"The possibility of checking documents of people of non-Slavic appearance only in some cases" is supported by $74 \%$ of the grown-up population of the region; young people are more categorical and think that "Checking documents of the people of non-Slavic appearance by the police must become a compulsory practice" $-56 \%$ of the interviewed came to such a conclusion.

$63.7 \%$ of the citizens of the region give a negative answer to the question: "Is there an intolerant attitude to people of another nationality and religion in your town and settlement?" $34 \%$ of the interviewed think, that in their town there are facts of intolerant attitude to people of other nationalities and religions, but do not see any serious problem in it.

The greater part of the interviewed sees the reason for conflicts between representatives of different nations in the difference of opinions, concerning national interests $(31,7 \%)$. A little less attention is paid to the variant "political difference of opinions" (29\%), the smallest number of answers was given to the variant "territorial difference of opinions" $(12 \%) .51 \%$ of the interviewed consider racial hostility to be the reason of conflicts, $32 \%$ of respondents chose "provocation from the side of extremist organizations".

$36 \%$ of the interviewed citizens of Vladimir region react positively to the fact that people of different nationalities live in their block of flats, but $58 \%$ of respondents react negatively to migrants. $11 \%$ of the interviewed showed indifference to this problem. A significant number of respondents react neutrally to the neighborhood with people of different nationalities $43 \%, 31 \%$ of the interviewed found the answer to the question difficult.

In the reference group of citizens in the age group $17-55,79 \%$ of respondents think that migrants must 
assimilate in the country of living. The opinion on the accepting the laws and traditions of a "receiving country" was categorical $-87 \%$ of all the interviewed are sure that migrants and refugees must strictly observe the laws and traditions and carry responsibility for their non-observance according to the laws of the receiving country.

Answering the question: "Do you support organizations opposing migrants?", the greater part of the interviewed thinks that organizations opposing migration are to be prohibited (43\%). $32 \%$ consider such organizations to be useful, but do not want to take an active part in their activity. $17 \%$ fully agree with the activity of such organizations and are ready to become their active members (this number was especially great in the reference group of young people aged 17-25 $29 \%$ ).

The answers of young people aged 17-25 are significant. The results of the analysis of youth interviewing allow one to come to the conclusion: young people, on the whole, have broad conceptions of such notions as xenophobia - 55\%, tolerance - $86 \%$, nationalism $-76 \%$, migrants and refugees $-90 \%$, extremism - 67\%, terrorism - 61\%. They are also familiar with the legislation of the Russian Federation, notably with the propositions of the Constitution, securing equality of all people irrespective of their sex, race and nationality $-85 \%$.

$20 \%$ of the interviewed young people experience hostility to representatives of other nationalities living on the territory of their town or district. $66 \%$ treat them neutrally. $14 \%$ of the interviewed react negatively, and $69 \%$ - positively and neutrally to other nationalities living in Russia, but on their historical territory.

$50 \%$ of the youth agree with the thesis that every nation must live on its historical territory. $52 \%$ of young people react neutrally to marriages between representatives of different nationalities, $24 \%$ are against such unions.

Also both grown-up population and youth express a strong desire to learn more about culture and traditions of other countries and nations living there.

$71 \%$ of respondents are not familiar with the activity of youth extremist organizations. $21 \%$ confessed that they are aware of such organizations activity. $47 \%$ of the interviewed found it difficult to define their attitude to migrants.

The survey results showing that the overwhelming number of young people stand for compulsory checking of documents of people of non-Slavic appearance $-50 \%$, can indicate to the existence of international tension in youth environment.

$44 \%$ of the interviewed young people aged 17-25 think that in their town (district) there is a problem of intolerant attitude to people of other nationalities and religions, but do not see any problem in it.

A considerable number of respondents react neutrally to the neighborhood with people of other nationalities and religions - $43 \%$, and $31 \%$ of the interviewed answered that the question was difficult for them.

The research showed that school pupils and students rather often face cases of intolerance on one or another national ground, it is proved by the following data. $14 \%$ of respondents met with different demonstrations of intolerance; $22 \%$ of the interviewed watched spreading of extremist leaflets, placards, etc.; 19\% watched meetings and public speeches of nationalists; $15 \%$ saw mass media publications offensive for a certain nationality and religion; $12 \%$ were witnesses of direct physical violence.

Many respondents of this group faced evident demonstrations of intolerance, notably: $22 \%$ watched spreading of extremist symbols, 19\% - meetings and public speeches of nationalists and extremists, $15 \%$ saw publications offensive for some nationalities in press, $14 \%$ met several cases of intolerance at once, $13 \%$ said that they never met such phenomena.

The greater number of citizens do not support nationalist organizations of different types: $54 \%$ of the interviewed are against the existence of such organizations and associations; $12 \%$ of respondents think that such organizations influence making political decisions by the authorities. $18 \%$ say that nationalist organizations give the possibility for the young people to express their civil stand, to preserve Russian culture and traditions, to defend orthodoxy. 19\% remark that organizations of a similar type fight with the mass inflow of migrants; $9 \%$ think that such organizations can influence the number of migration streams and a criminogenic situation in the region.

Answering the question about the demonstration of intolerance towards the representatives of different national diasporas living in their town, 59\% of respondents answered that they never showed intolerance to any national minority. $19 \%$ of respondents recognize that a nationality of a person is a factor of intolerance from their side, $26 \%$ showed their intolerance to people not because of their nationality, but on other reasons, $7 \%$ found it difficult to answer this question.

On the basis of the survey, one can say that the cases of humiliation of a person because of his nationality are not rare and are met rather often both in mass media and in everyday life. The following data confirm this: $29 \%$ of the interviewed observed personally the cases of humiliation of a person because of his nationality or religion, $27 \%$ saw such cases on TV, $14 \%$ heard about such cases from their acquaintances, $13 \%$ read about it in newspapers and only $11 \%$ never faced situations of the similar type.

Having analyzed all the data received in the course of research, one can come to the conclusion about the existence of the polyvalent attitude of the society to the problem of migration and tolerance of cultures. A serious concern is caused by the existence of the signs of xenophobia in a great number of young people, living in small towns of the region, which is connected with socio-economic problems of the given regions. The position of the grown-up population is more tolerant, which can be explained by the heritage of the Soviet Union, when the idea of friendship of peoples in an international multicultural state was actively propagandized and ideologically substantiated. 
Our research resulted in the development of practical recommendations to the mass media of Vladimir region, which can be also applied in the work of mass media in other regions of the Central region of the Russian Federation.

The basic recommendations, which, to our mind, are priority ones, influencing the mass consciousness of citizens, are the following:

- while composing the plot or article about the representatives of different ethnic, religious, social, or age-related groups, one should not adhere to evident or hidden stereotypes, concerning the characteristics inherent to these groups;

- to pay more attention to the survey of culture and traditions of nationalities, traditionally living on the territory of Vladimir region or migrants;

- in case of covering an international conflict, not to come to hasty conclusions on the fact that a conflict was provoked by a hostile attitude to a person or group;

- while giving news of a criminal character, not to emphasize the nationality of participants of the event;

- to popularize in Mass Media and the Internet, a positive experience of multicultural interaction (including world and historic experience).

The following practical recommendations would be effective, to our mind, for educational institutions of Vladimir region:

- to conduct theme events ("We are different, but we are together", "Tolerance and we", "Tolerance to yourself and others", "Tolerance means...", "Key to tolerance", "Traditions and customs of my country", "Children of different nations live dreaming of friendship", "Movement to mutual understanding", "On informal extremist associations of teenagers", etc.;

- round table talks, including those with role play tasks and problem questions ("To live in peace with yourself and others", "Tolerance - harmony of diversity", "What does national and religious intolerance result in?, "What does it mean to respect another person?", "Laws of tolerance", etc.;

- contests of creative works of students of - essays, wall newspapers, placards, magazines, video materials, etc., devoted to the problem of tolerance;

- amateur concerts to show the art of different nationalities;

- meetings with specialists, working in the sphere of studying tolerance problems;

- talks, conducted with representatives of authorities, mass media, religious confessions, ethnocultural communities;

- trips to museums, cultural centers, exhibitions, etc.;

- organizing theme book exhibitions in the libraries of educational institutions;

- celebrations, festivals of national cultures, festivals of friendship of nations.

Local government bodies can be offered to conduct events including integration people of other nationalities and religions into social life. To our mind positive results can be achieved by means of:

- organizing concerts, exhibitions, theme events with the participation of representatives of different cultures and ethnoses. It will contribute to attracting public attention to the problems of multicultural interaction;

- organizing public discussions, connected with social assessment of events of national or ethnoconfessional trend;

- attracting representatives of different cultures, living on the territory of Vladimir region, to the problems of organizing work for developing multicultural interaction.

Following these recommendations, to our mind, will contribute to the upbringing of culturally educated, tolerant modern citizens, respecting and accepting somebody's right to a different opinion, different culture, different habits and ways, to create conditions for more positive relations between representatives of different cultures in the united socio-economic area, it will reduce the number of conflicts, arising on the ground of national hostility and intolerance, it will allow every nation to realize its constitutional right to a free choice of the place of living and religion.

\section{References}

1. S. Benhabib, Claims of culture. Equality and diversity in the global era (Logos, Moscow, 2003),

2. M. Delyagin, The practice of globalization of the game and the rules of a new era (Moscow, 2000)

3. M.A. Abramova, Philosophy of Education 2(23), 44-50 (2008)

4. A.G. Asmolov, Tolerance: from Utopia to Reality, Towards a Tolerant Consciousness, Sense (Moscow, 2000).

5. J. Laurence, European Sociological Review 27(1), 70-89 (2011)

6. Ø. Gaasholt, L. Togeby, Political Behavior, 17(3), 265-285 (1995)

7. J. Thijs, M. Verkuyten, Journal of Educational Psychology 84(1), 1-21 (2014)

8. S. Jha, American Political Science Review 107(4), 806-832 (2013)

9. K. Godwin, C. Ausbrooks, V. Martinez, Phi Delta Kappan 82(7), 542-546 (2001)

10. A. Kokkonen, P. Esaiasson, M. Gilljam, Scandinavian Political Studies 33(4), 331-355 (2010)

11. F.D. Bean, R.G. Cushing, C.W. Haynes, J.V.W. Van Hook, Social Science Quarterly 78(2), X-268 (1997)

12. G.F. Yusupova, J. Podgorecki, N.G. Markova, International Journal of Environmental and Science Education 10(4), 561-570 (2015)

13. O.E. Fomina, International Research Journal 06 (60), 1, 96-99 (2017) 